Provided for non-commercial research and education use. Not for reproduction, distribution or commercial use.

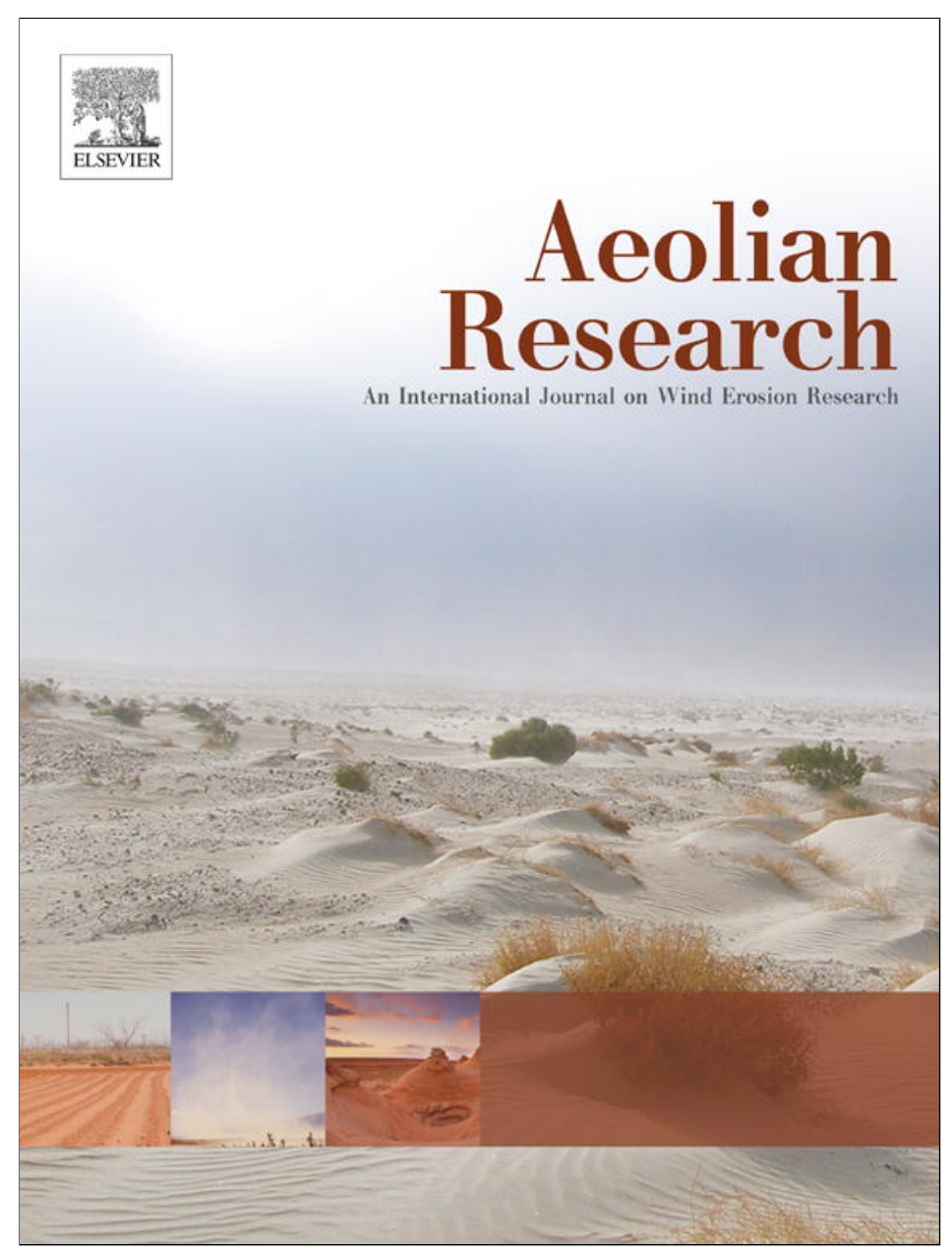

(This is a sample cover image for this issue. The actual cover is not yet available at this time.)

This article appeared in a journal published by Elsevier. The attached copy is furnished to the author for internal non-commercial research and education use, including for instruction at the authors institution and sharing with colleagues.

Other uses, including reproduction and distribution, or selling or licensing copies, or posting to personal, institutional or third party websites are prohibited.

In most cases authors are permitted to post their version of the article (e.g. in Word or Tex form) to their personal website or institutional repository. Authors requiring further information regarding Elsevier's archiving and manuscript policies are encouraged to visit:

http://www.elsevier.com/copyright 
Review Article

\title{
Summary of the Third International Planetary Dunes Workshop: Remote Sensing and Image Analysis of Planetary Dunes, Flagstaff, Arizona, USA, June $12-15,2012$
}

\author{
Lori K. Fenton $^{\mathrm{a}, *}$, Rosalyn K. Hayward ${ }^{\mathrm{b}}$, Briony H.N. Horgan ${ }^{\mathrm{c}}$, David M. Rubin ${ }^{\mathrm{d}}$, Timothy N. Titus ${ }^{\mathrm{b}}$, \\ Mark A. Bishop ${ }^{\mathrm{e}, \mathrm{f}}$, Devon M. Burr ${ }^{\mathrm{g}}$, Matthew Chojnacki ${ }^{\mathrm{g}}$, Cynthia L. Dinwiddie ${ }^{\mathrm{h}}$, Laura Kerber ${ }^{\mathrm{i}}$, \\ Alice Le Gall ${ }^{\mathrm{j}}$, Timothy I. Michaels ${ }^{\mathrm{a}}$, Lynn D.V. Neakrase ${ }^{\mathrm{k}}$, Claire E. Newman ${ }^{\mathrm{l}}$, Daniela Tirsch $^{\mathrm{m}}$, \\ Hezi Yizhaq ${ }^{\mathrm{n}}$, James R. Zimbelman ${ }^{\mathrm{o}}$
}

${ }^{a}$ Carl Sagan Center at the SETI Institute, 189 Bernardo Ave., Suite 100, Mountain View, CA 94043, USA

${ }^{\mathrm{b}}$ United States Geological Survey, Astrogeology Science Center, 2255 N. Gemini Dr., Flagstaff, AZ 86001, USA

${ }^{c}$ Arizona State University, School of Earth and Space Exploration, P.O. Box 876305, Tempe, AZ 85287, USA

${ }^{\mathrm{d}}$ United States Geological Survey, 400 Natural Bridges Dr., Santa Cruz, CA 95060, USA

e Planetary Science Institute, 1700 E. Fort Lowell Road, Suite 106, Tucson, AZ 85719, USA

${ }^{\mathrm{f}}$ School of Earth and Environmental Sciences, University of Adelaide, SA 5005, Australia

${ }^{g}$ Planetary Geosciences Institute, Department of Earth and Planetary Sciences, University of Tennessee Knoxville, Knoxville, TN 37996, USA

${ }^{\mathrm{h}}$ Geosciences and Engineering Division, Southwest Research Institute ${ }^{\circledast}, 6220$ Culebra Road, San Antonio, TX 78238, USA

${ }^{\mathrm{i}}$ Labroratoire de Météorologie Dynamique du CNRS, Université Paris 6, Paris, France

${ }^{\mathrm{j}}$ Laboratoire Atmosphères, Milieux, Observations Spatiales (LATMOS-UVSQ), Paris, France

${ }^{k}$ Planetary Data System Atmospheres Node, Department of Astronomy, New Mexico State University, Las Cruces, NM 88003, USA

${ }^{1}$ Ashima Research, 600 S. Lake Ave., Suite 104, Pasadena, CA 911006, USA

m Institute of Planetary Research, German Aerospace Center (DLR), Rutherfordstrasse 2, 12489 Berlin, Germany

${ }^{\mathrm{n}}$ Solar Energy and Environmental Physics, BIDR, Ben-Gurion University, Midreshet Ben-Gurion, Israel

${ }^{\circ}$ Center for Earth and Planetary Studies, National Air and Space Museum, MRC 315, Smithsonian Institution, Washington, DC 20013-7012, USA

\section{A R T I C L E I N F O}

\section{Article history:}

Received 2 October 2012

Revised 9 October 2012

Accepted 10 October 2012

\section{Keywords:}

Aeolian processes

Bedform dynamics

Bedform morphology

Sand provenance

Meeting summary

\begin{abstract}
A B S T R A C T
The Third International Planetary Dunes Workshop took place in Flagstaff, AZ, USA during June 12-15, 2012. This meeting brought together a diverse group of researchers to discuss recent advances in terrestrial and planetary research on aeolian bedforms. The workshop included two and a half days of oral and poster presentations, as well as one formal (and one informal) full-day field trip. Similar to its predecessors, the presented work provided new insight on the morphology, dynamics, composition, and origin of aeolian bedforms on Venus, Earth, Mars, and Titan, with some intriguing speculation about potential aeolian processes on Triton (a satellite of Neptune) and Pluto. Major advancements since the previous International Planetary Dunes Workshop include the introduction of several new data analysis and numerical tools and utilization of low-cost field instruments (most notably the time-lapse camera). Most presentations represented advancement towards research priorities identified in both of the prior two workshops, although some previously recommended research approaches were not discussed. In addition, this workshop provided a forum for participants to discuss the uncertain future of the Planetary Aeolian Laboratory; subsequent actions taken as a result of the decisions made during the workshop may lead to an expansion of funding opportunities to use the facilities, as well as other improvements. The interactions during this workshop contributed to the success of the Third International Planetary Dunes Workshop, further developing our understanding of aeolian processes on the aeolian worlds of the Solar System.
\end{abstract}

(c) 2012 Elsevier B.V. All rights reserved.

\footnotetext{
* Corresponding author. Address: 189 Bernardo Ave., Ste. 100, Mountain View, CA 94043, USA. Tel.: +1 650810 0212; fax: +1 6509629419.

E-mail address: Ifenton@carlsagancenter.org (L.K. Fenton).
} 


\section{Contents}

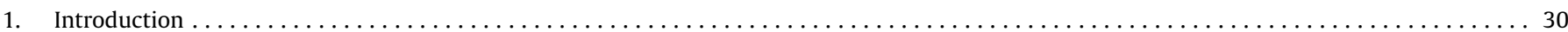

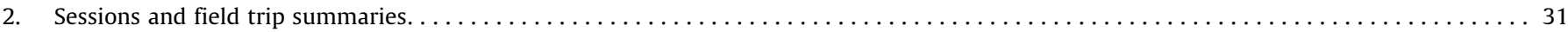

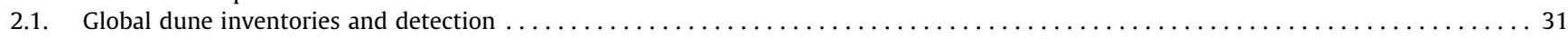

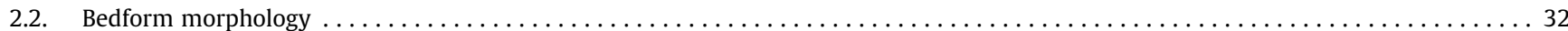

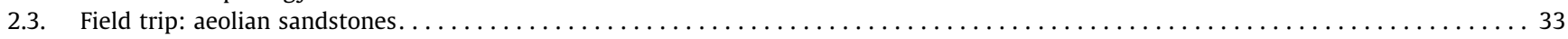

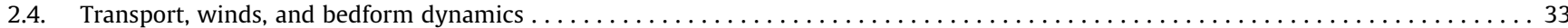

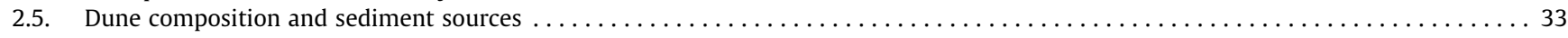

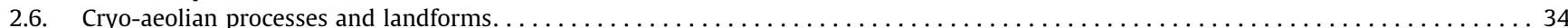

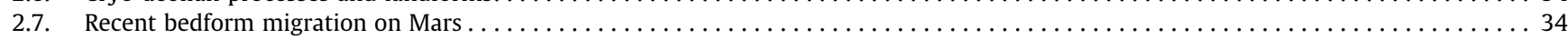

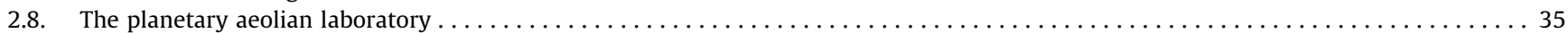

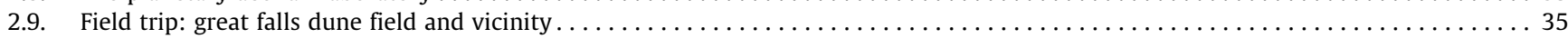

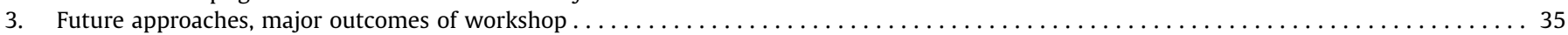

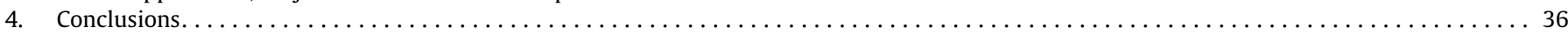

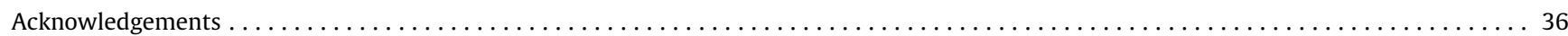

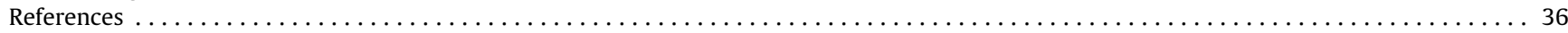

\section{Introduction}

In the last decade and a half, numerous spacecraft have flown by, orbited, or landed on Mars and Titan (the largest satellite of Saturn), providing a wealth of new data on these worlds. Both planetary bodies have surfaces heavily modified by aeolian processes, which interact with other sedimentary processes to significantly alter the surfaces that we view today. These other processes include fluvial, lacustrine, glacial and periglacial processes (on Mars), and methane precipitation (on Titan). Visits to other Solar System worlds (such as New Horizons, which will fly past Pluto and its moons in 2015) may reveal the presence of aeolian activity in even more extreme environments. Viewing these worlds in unprecedented detail has and will transform the study of their surfaces from the perspective of an astronomer to the perspective of a geologist (see Fig. 1). The natural result of this progression is a desire and necessity for more discourse and collaboration with terrestrial geologists, who may in turn benefit from studying familiar geological processes occurring in unfamiliar settings. Scientific questions regarding dunes and other aeolian features in the Solar System are similar to those asked by terrestrial aeolian scientists:

- What processes control the formation of aeolian sand grains?

- What factors control sand availability?

- How does the unique local climate influence bedform morphodynamics, and how can bedform morphodynamics be used to study regional or even global climate change?

- How can sand composition be used to determine sand provenance and maturity?

- How do boundary conditions in each sand system affect sediment transport, accumulation, and dune field patterns?
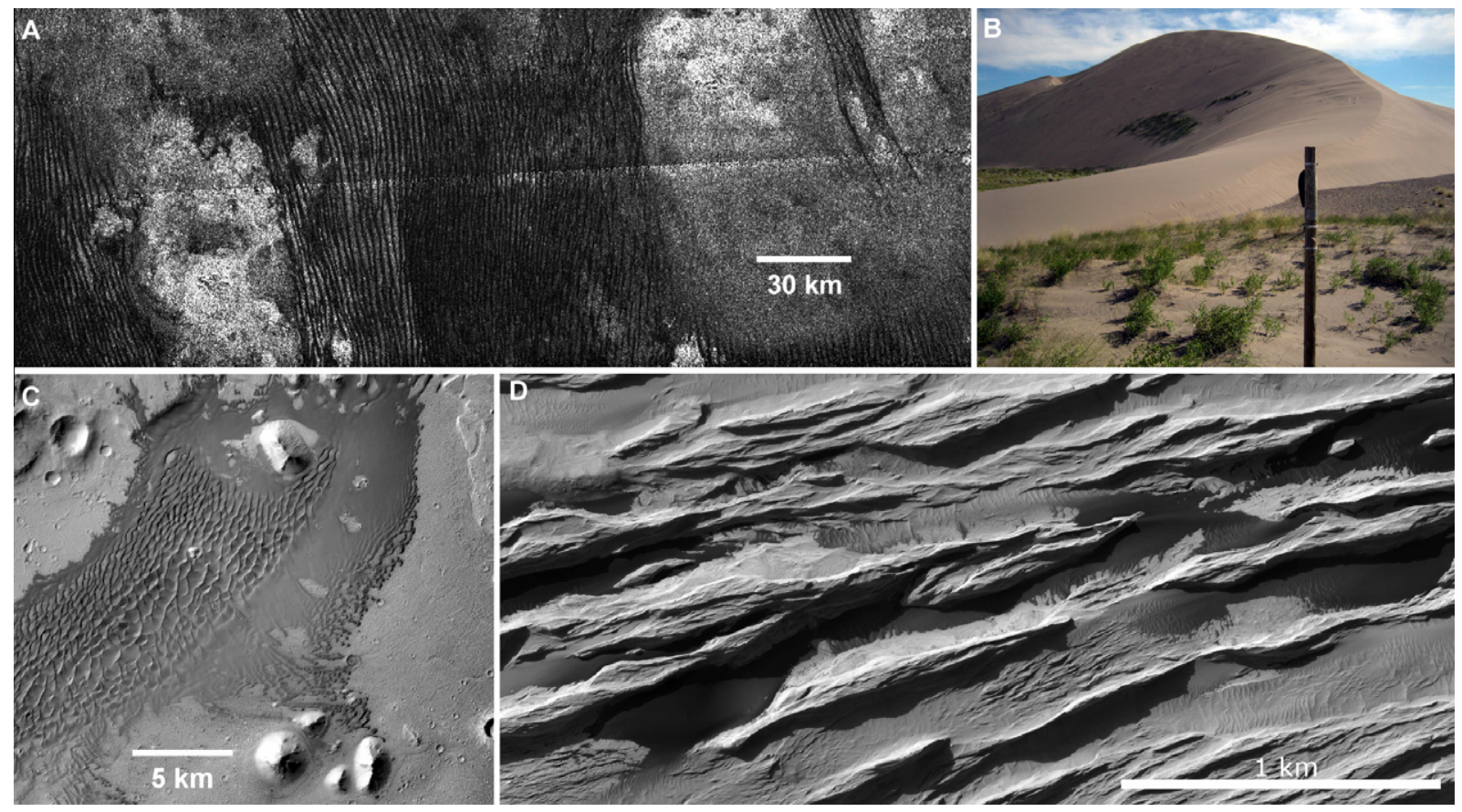

Fig. 1. Examples of planetary dune study areas. (A) Radar-dark linear dunes in the Shangri-La region of Titan (Cassini Radar SAR swath T55), (B) an arm of the Bruneau Dunes in Idaho, USA (image by J.R. Zimbelman), (C) a dune field in Ganges Chasma on Mars (Context Camera image P19_008536_1726), and (D) sand and ripples within the yardangs of the Medusae Fossae Formation on Mars (HiRISE image PSP_008621_1750). 
Table 1

List of planetary dune workshops.

\begin{tabular}{|c|c|c|c|}
\hline Workshop & Location & Field trip & Special issue \\
\hline $\begin{array}{l}\text { Planetary Dunes Workshop: A Record of Climate Change (April 29-May } \\
\text { 2, 2008) }\end{array}$ & $\begin{array}{l}\text { Alamogordo, } \\
\text { NM, USA }\end{array}$ & White Sands National Monument & $\begin{array}{l}\text { Geomorphology, v. } 121 \text { Editors: M.C. } \\
\text { Bourke, L.K. Fenton, N. Lancaster }\end{array}$ \\
\hline $\begin{array}{l}\text { Second International Planetary Dunes Workshop: Planetary Analogs - } \\
\text { Integrating Models, Remote Sensing, and Field Data (May 18-21, } \\
\text { 2010) }\end{array}$ & $\begin{array}{l}\text { Alamosa, CO, } \\
\text { USA }\end{array}$ & $\begin{array}{l}\text { Great Sand Dunes National Park } \\
\text { and Preserve }\end{array}$ & $\begin{array}{l}\text { Earth Surface Processes and Landforms, } \\
\text { in preparation Editor: M.A. Bishop }\end{array}$ \\
\hline $\begin{array}{l}\text { Third International Planetary Dunes Workshop: Remote Sensing and } \\
\text { Image Analysis of Planetary Dunes (June 12-15, 2012) }\end{array}$ & $\begin{array}{l}\text { Flagstaff, AZ, } \\
\text { USA }\end{array}$ & $\begin{array}{l}\text { Navajo and Entrada Sandstones, } \\
\text { Grand Falls Dune Field and Vicinity }\end{array}$ & $\begin{array}{l}\text { Icarus, planned Editor: J.R. } \\
\text { Zimbelman }\end{array}$ \\
\hline
\end{tabular}
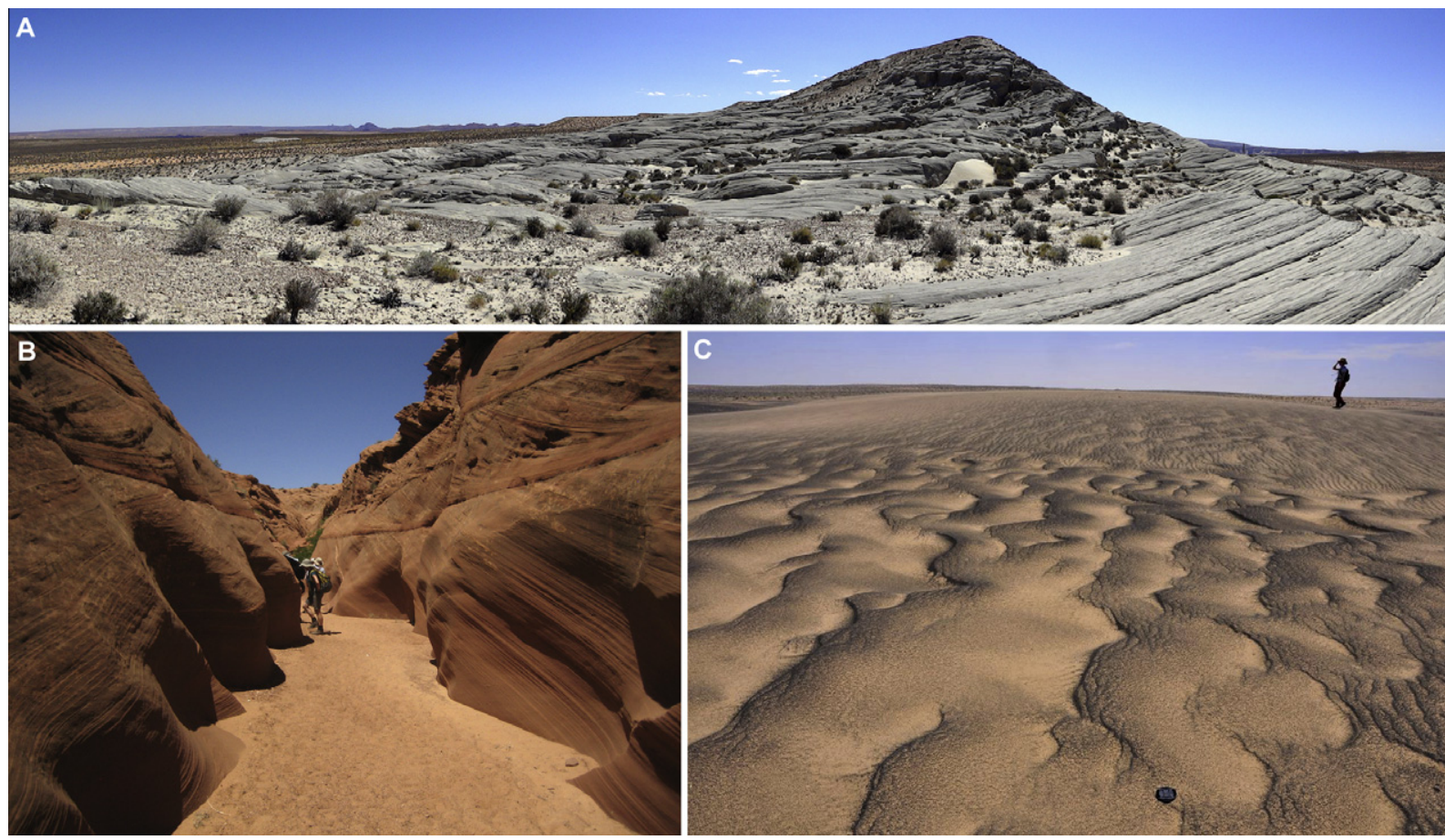

Fig. 2. Field trip sites. (A) Entrada Sandstone, exposing a complex oblique dune with superimposed secondary transverse dunes (image by B.H.N. Horgan), (B) Navajo Sandstone, with crossbedding revealed in the steep walls of a wash (image by J.R. Zimbelman), and (C) Grand Falls Dune Field, showing low barchans and coarse-grained ripples composed of finer, bright sand and coarser, dark granules (image by H. Yizhaq).

The International Planetary Dunes workshop was the third in a series of meetings, listed in Table 1 (Titus et al., 2008, 2010, 2012; Fenton et al., 2010). The goal of all such workshops has been to foster collaboration between terrestrial and planetary aeolian researchers, including those who perform studies with models, in laboratories, in the field, and with remote sensing data. Recent work attests to the vigor of research in this rapidly expanding field (Zimbelman, in review/this issue?). Timothy N. Titus (USGS, Flagstaff) convened this meeting with a scientific organizing committee including Mary Bourke (Planetary Science Institute), Lori Fenton (Carl Sagan Center at the SETI Institute), Rosalyn Hayward (USGS, Flagstaff), Briony Horgan (Arizona State University), Nick Lancaster (Desert Research Institute), and David Rubin (USGS, Santa Cruz). As with the two preceding workshops, this one was designed to have an intimate atmosphere to encourage discussion; a total of 48 participants registered. Each speaker was given $30 \mathrm{~min}$ to talk and strongly encouraged to leave half of that time open for questions. Extended abstracts follow the standard two page format of the Lunar and Planetary Institute, and may be found at the meeting website: http://www.lpi.usra.edu/meetings/dunes2012/.

\section{Sessions and field trip summaries}

The workshop consisted of six oral sessions (28 presentations) and one poster session ( 24 posters). The first day began with a keynote dedication by Jim Zimbelman, who highlighted the many and significant accomplishments of the late Ronald Greeley (August 25, 1939-October 27, 2011). Greeley was an inspiration to many, as well as a major force behind many different aspects of planetary geology; a list of 54 peer-reviewed publications discussing just aeolian subjects is available in the abstract by Zimbelman (2012). On the second day, David Rubin, Amy Draut, and Rosalyn Hayward led a full-day field trip to the Navajo and Entrada Sandstones in northeastern Arizona (see Fig. 2). The evening before the field trip, the topic of aeolian sandstone was introduced in a keynote talk by Lauren Edgar, summarizing the stratigraphy of aeolian cross-bedding found in Meridiani Planum on Mars (Edgar, 2012). Nathan Bridges led a discussion regarding the present state and future of the Planetary Aeolian Laboratory, currently managed by David Williams at Arizona State University. Finally, an informal field trip was held the day after the workshop ended, with stops at the Grand Falls dune field, a dry lake bed, and a basaltic sand sheet.

\subsection{Global dune inventories and detection}

The first session included talks on both the occurrence and nature of planetary dunes on bodies ranging from Mars to Pluto. A common theme was the desire to connect dune occurrence or morphology with climate, as well as the challenges in attempting this connection. Ewing (2012) compared the planetary boundary 
conditions that impact the amount and type of dunes across different bodies from Earth to Pluto: sediment sources and availability, thresholds and transport capacity of wind, factors affecting dune growth rates, and also those affecting accumulation and preservation of bedforms. A major question considered by Ewing (2012) was that dunes seem ubiquitous in the Solar System, but do we expect them on the surface of Pluto? Given the low atmospheric density on Pluto, winds of $\sim 130 \mathrm{~m} / \mathrm{s}(\sim 300 \mathrm{mph})$ at $\sim 1 \mathrm{~m}$ height may be required to overcome the saltation threshold. It is not clear if such winds exist or if unfrozen sediment is available for transport.

Kreslavsky and Bondarenko (2012) discussed possible sources of sediment on Venus (e.g., impacts or volcanism) and raised the question of whether aeolian transport is ongoing or episodic on this planet. Geological periods of transport could be brief, possibly initiated by impacts and lasting only until the sand is moved to traps, lithified or destroyed. The authors highlighted that progress is currently limited by the paucity of observations, as no aeolian bedform was seen by the Venera landers or orbiters, only two dune fields were recognized in the Magellan SAR images, and possible asymmetric microdunes were inferred from backscattering anisotropy in the southern hemisphere of Venus (e.g., Greeley et al., 1997). Furthermore, there is major uncertainty regarding the wind regime and near-surface winds on Venus.

Using Cassini radar and radiometry data, Le Gall et al. (2012) showed that Titan's dunes are quite expansive, probably covering $\sim 13 \%$ of the surface and confined to the equatorial belt, with the morphometry of the giant dune fields controlled by both altitude and latitude (see Fig. 1A). In more elevated and higher-latitude regions, dunes tend to be narrower or more widely spaced and the 'sand' cover in the interdune areas seems to be thinner, suggesting less sedimentary material, which has strong implications for Titan's geological and climatic history. In particular, the authors suggested that Titan's dunes could be composed of a single dune generation that has evolved over a timescale as long as that of the terrestrial Croll-Milankovitch cycles ( $\sim 45 \mathrm{kyr})$, a theme echoed by others studying Titan's dunes (see Section 2.4).

Newman et al. (2012) used the Gross Bedform-Normal Transport method (Rubin and Hunter, 1987a) to predict bedform orientations on Mars and Titan, concluding that global-scale winds were inadequate in regions with distinct local circulations (such as Gale Crater dunes, which appear strongly sensitive to local topography). The authors also discussed the difficulties of predicting equatorial dunes with an eastward resultant transport direction on Titan, noting that although the observed dune locations could be predicted by a model that included estimated Titan topography with high saltation thresholds, the modeled dunes were rather inconsistent with observed dune orientations and morphology. This inconsistency raised a new key question: to what extent can dunes and dune field patterns in general be used as climate indicators?

\subsection{Bedform morphology}

A diversity of aeolian research was demonstrated in the session on bedform morphology, where two key themes emerged around spatial scale and analog study of aeolian bedforms. Building upon research that was embryonic during the previous workshop in Alamosa, Colorado, in 2010, the presentations showed significant advances in the investigation of bedform morphology using field comparisons and automated approaches to the analysis of image data. In particular, the session showcased the interdisciplinary methodology that has been developed in the last 2 years to better interpret ripples, dunes, draa and ergs at time scales that range across the Quaternary for Earth (within the last 2.588 million years) and the late-Amazonian for Mars (within the last several hundreds of millions of years). Presentations on classification, genesis and evolution of mega-scale dunes and dune fields both con- trasted and complemented papers on granule ripples and Transverse Aeolian Ridges (TARs; Berman et al., 2011).

Two of the presentations focused on the development of terrestrial mega-dunes or draa. Valdez (2012) furthered discussion from the previous workshop on the draa-like feature comprising the Great Sand Dunes National Park and Preserve (GSDNPP), Colorado, and its use as an analog for topographically constrained dune fields in craters, valleys, and other depressions on Mars. Dune field development and processes contributing to the GSDNPP dune fields were described along with the range of morphologies and the variety of environmental settings and wind regimes that occur in the growth of a mega-dune. In particular, interannual variations in the morphology and migration rates of star and parabolic dunes are indicative of how dune morphology reflects changes in sand influx and interactions with small-scale topography (i.e., trees). Similarly, Bishop (2012) described ongoing research into the evolution of crescentic and stellate mega-dunes for the Al Liwa basin of the Empty Quarter (Ar Rub' al Khali sand sea) where changes in environmental conditions and sand flux were used to explain transitional modifications in dune size, population and pattern across the depocenter. Crescentic dunes dominate the north of the basin whereas megadunes of stellate or star form are a major landform of the south-eastern reaches. Their development into dune fields is determined by the style and rate of dune-dune interactions, the boundary conditions imposed by a multi-modal wind regime, fluctuating groundwater levels, and sediment availability under an assortment of climatic conditions throughout the Quaternary. The Al Liwa basin offers an analog for better understanding erg development on Mars.

In contrast to the research around mega-scale landscape features, three papers used terrestrial analogs to investigate the origin and development of granule ripples and their possible connection to the ubiquitous TARs of Mars (some of these bright bedforms are visible between the yardangs in Fig. 1D). The morphological development and potential migration of large-scale ripple bedforms on Earth challenges the existing knowledge of their origin and activity on Mars. Investigating some of the coarsest gravel mega-ripples on Earth, de Silva et al., 2012 characterized the sedimentology and field relationships of bedforms sourced from ignimbrites, with grain sizes reaching up to $5 \mathrm{~cm}$, in the Puna of Argentina. These features are analogous to ripples seen on the Meridiani plain of Mars, and the spatial relationships involving topography, bedrock and form are comparable with that for some TARs. This comparison suggests that the source of the sediments for dark dunes on Mars may also be locally sourced volcaniclastic materials as seen on the Argentinean Puna (see Section 2.5). The Puna ripples preferentially form on topographic highs and excavate inter-ripple terrain, such that they are dynamic but nonmigrating bedforms, an occurrence not typically considered for aeolian bedforms but possibly identified on Mars by Montgomery et al. (2012). Bridges et al., 2012a compared the mega-ripples of the Argentinian Puna with wind tunnel modeling, finding that the pumice and lithic grains are indeed active in the present wind regime. Together, these two papers indicate that the surface veneer of grains and the underlying topography may control the activity or inactivity of mega-ripples and TAR bedforms for both Earth and Mars. The issue of TAR origin was also explored using another terrestrial ana$\log$ site, the Bruneau Dunes of south-central Idaho (see Fig. 1B; Zimbelman and Scheidt, 2012). Using transverse profiles, the topographic character of reversing dunes was shown to be similar to the morphology of large TAR bedforms, suggesting that reversing wind profiles may play a role in TAR development. This work extends that previously presented by Zimbelman and colleagues at the 2010 workshop, and further demonstrates the application of topographic profiles to define the morphometric and morphologic characters of TARs and the likely analogs these have on Earth. 
The final two papers in this session concentrated on image analysis of satellite data from Mars. Berman et al. (2012) used a suite of orbital time series of images to investigate sediment source, local topography and geology, and the relationships between TARs and dark dunes to further constrain the mechanisms of TAR development and to examine whether changes in morphology and position occur with time. Vaz and Silvestro (2012) used ripples as a test-bed for demonstrating how Object Based Image Analysis (OBIA) could be used to define ripple patterns and morphological variability of ripples, and gave estimates of migration rates using temporal image series from the High Resolution Science Experiment (HiRISE) camera aboard the Mars Reconnaissance Orbiter. Both these image analysis studies parallel much that has been discussed in the aforementioned terrestrial analog sites.

In summary, this series of presentations demonstrated that the perspectives derived from the coupling of terrestrial field comparisons with orbital image data have significantly advanced the understanding of form and process of bedforms for all planetary bodies with an atmosphere and observable surface.

\subsection{Field trip: aeolian sandstones}

The fieldtrips for the first two Planetary Dunes Workshops visited modern dune fields, but the fieldtrip for this workshop examined aeolian sandstones that were formed approximately 200 million years ago. Following the route of a 1987 field trip for the Geological Society of America (Rubin and Hunter, 1987b), participants first visited Waterholes Canyon, where the Navajo Sandstone displays outstanding examples of the three primary aeolian stratification types (wind-ripple stratification, grainflow, and grainfall); cyclic cross-bedding deposited by winds that changed direction seasonally (giving a visible record of annual dune migration); nodules interpreted to be replaced evaporites; and large-scale deformational bands and associated soft-sediment deformation (see Fig. 2B). The group then visited an outcrop of the Entrada Sandstone that was deposited by an oblique linear dune. The outcrop contains compound cross-bedding that records both across-crest sand transport (lateral migration of the main dune) and along-crest sand transport (superimposed dunes migrating along the length of the large dune), thereby demonstrating the oblique orientation of the dune (see Fig. 2A).

Modern dune fields give a more complete view of dune morphology than aeolian sandstones, but sandstones display a more thorough record of the dune motion and behavior, as well as the physical processes that deposit sand and the chemical processes that alter the deposits. Some of these structures are difficult or impossible to observe on modern dunes because they form too slowly (centuries or millennia of dune migration), or too infrequently (sediment liquefaction), or because they form in the subsurface (evaporite nodules). Dave Rubin and Amy Draut (USGS, Santa Cruz) led the field trip with help from Rosalyn Hayward (USGS, Flagstaff), and Gerald Bryant (Dixie State College) shared his work on deformational structures.

\subsection{Transport, winds, and bedform dynamics}

This session of the workshop focused on the development of new techniques to study bedform evolution. If the Kok (2010) saltation maintenance threshold and hysteresis behavior for Mars is correct, then normal aeolian ripples at Eagle crater on Mars may form well below the fluid threshold (Yizhaq and Kok, 2012). This conclusion may also partially explain the recently observed intense aeolian activity on Mars (e.g., Bridges et al., 2012b) without the need for strong winds exceeding those predicted by global climate models. A more detailed "map" of the 2D and 3D particulate bedform types produced by the asymmetry of the formative flow direction and magnitude was presented (Rubin, 2012). It suggests a unifying model for explaining the planform straightness of ripples and dunes in air and water. The main idea of the model is that physical coupling along the crest of a bedform is required to produce straight crests (transverse stability) and that along-crest flow and sand transport provide effective physical mechanisms for that coupling. A new technique, inverse gross bedform normal transport, was presented that uses image-based crestline mapping to estimate formative wind fields across areas of aeolian bedforms (Fenton and Beyer, 2012). Laboratory studies of particulate bedforms indicate that the transition between archetypes (e.g., longitudinal, oblique, transverse) is perhaps highly nonlinear in relation to the time spent under each flow direction regime (Reffet et al., 2012). An earth-based method that uses mesoscale atmospheric models to dynamically downscale historical weather data to better understand local- and regional-scale controls on the long-term evolution of aeolian features was presented (Michaels, 2012). Computational Fluid Dynamics (CFD) atmospheric modeling at meter-scales has produced some promising early results over a Mars dune field, demonstrating the differing flow patterns on dunes from various incident winds, and is an avenue of future progress (Jackson et al., 2012).

A second theme regarding bedform dynamics centers on Titan's extensive sand seas (see Fig. 1A). In the past several years, a significant amount of mapping has been done, and global climate model results appear to be consistent with some, but perhaps not all observations (Radebaugh et al., 2012). Repeated near-infrared brightening events during Titan's northern spring equinox appear to be consistent with dust storms, which would indicate recent aeolian activity in the vicinity of the equatorial dune belt (Rodriguez et al., 2012). Long-term changes in global climate are being considered as boundary conditions to dune-building processes. Hayes et al. (2012) propose that changes in Titan's orbital parameters (similar to Milankovitch cycles on Earth) are affecting the climate and wind regime strongly enough to reorient the observed dune patterns. The development of dunes on Titan appears to be regulated by a balance between fluvial and aeolian processes, which regulates the latitudinal restriction of the dunes (Lorenz, 2012). In contrast, the interaction between fluvial and aeolian sediment on Earth is complex and sensitive to changes in local conditions (Draut and Rubin, 2012); it remains to be seen whether Titan's sand seas are also impacted by such small-scale processes.

\subsection{Dune composition and sediment sources}

Dune compositions and sediment sources were identified as key areas for research during the Second Planetary Dunes Workshop (Fenton et al., 2010), and new work was presented on both topics in this session. The presentations focused mainly on Martian dunes, with one terrestrial analog. Knowledge of a dune's composition can aid in determining the physical properties of its saltating grains and the chemical properties of possible dune-cementing agents. Transport pathways are readily identified in terrestrial deserts; combining visible and thermal infrared imaging from ASTER data has proven to be valuable in tracking bedform migration and locating the sources of different sand populations (Scheidt, 2012). Determination of the source of the sediment feeding a dune field permits the characterization of the sediment cycle on a broader scale. For example, relatively low albedo ("dark") dunes are often found in craters and canyons on Mars (see Fig. 1C). Close scrutiny of craters with dark dunes has revealed that there are often dark layers exposed in the crater walls which appear to supply dark sand to the dunes (Tirsch and Jaumann, 2012). Dunes found in the deep chasmata near Valles Marineris were also found to be compositionally linked to wall strata using spectroscopic techniques (Chojnacki et al., 2012a). Investigation of six dune fields suggests that local 
sources are common across the planet (Bachman et al., 2012). These proximal sources for the dark dunes indicate that the sediment need not be blown into the depressions from distant sources, although they raise the question of why dark layers are present in the wall. Even in cases where dark layers are not seen proximal to dark dune deposits, a local source is still possible. A relatively high albedo ("light") terrestrial pyroclastic flow deposit was found by Burr et al. (2012) to produce dark, sand-sized particles due to differential erosion. This finding suggests that the numerous dark sand deposits discovered near and within the Medusae Fossae Formation (a fine-grained, light, and possibly pyroclastic deposit near the Martian equator, see Fig. 1D), could be formed of particles emerging from the formation itself, rather than transported from afar (Burr et al., 2012). When combined with a broader geomorphic study of the Medusae Fossae Formation (Kerber et al., 2012), it is likely that more sand sources will be identified and placed into the geologic context of the region. It has been hypothesized that the sand found in Martian dune deposits had its ultimate source as volcaniclastic sediments, either as mafic pyroclastic ash or as fragments of eroded basalt, both of which have been identified in terrestrial analog studies (Edgett and Lancaster, 1993; Tirsch et al., 2011, 2012). In support of the pyroclastic hypothesis, new results show that nearinfrared spectra of the dark north polar erg are consistent with a large (80-90\%) proportion of iron-rich glass (Horgan and Bell, 2012a), and that glass is a major component of dune fields across the martian surface (Horgan et al., 2012a). Several important questions remain: How heterogeneous are the dark sediment layers on Mars? Do they have similar ages? An origin from buried pyroclastic ash layers may suggest somewhat similar regional ages and compositions. How does the sediment change as it moves further from the source? How is it weathered (chemically and physically)? How can volcanic glass and impact glass be distinguished? While most of the work conducted focused on dark dunes, relatively light-toned bedforms (i.e., TARs) also exist on Mars. What is the origin of these light sediments, and why do they form different bedforms than dark sediments (see Section 2.2)? It has been hypothesized that this light sediment also originates from explosive eruptions (Edgett, 1997). If so, how are these eruptions different than those producing dark sand?

\subsection{Cryo-aeolian processes and landforms}

This session focused on studies that investigate the important role of ice in the evolution of planetary aeolian systems. Several researchers followed a suggestion from the previous workshop (Fenton et al., 2010) to investigate how aeolian and cryogenic processes interact, including such processes as nival (snow-related) and periglacial (perennially sub-freezing temperatures). Terrestrial analogs provided a basis for this session. Lorenz and Valdez (2012) described their time-lapse observations of surficial niveo-aeolian (i.e., snow and sand) deposition on a large parabolic dune at the GSDNPP of Colorado. Dinwiddie et al. (2012a) reduced an 18 year time series of meteorological data from Kobuk Valley National Park to the annual average environmental conditions that influence atmospheric forcing of the Great Kobuk Sand Dunes (GKSD) in northwestern Alaska. The historical meteorological record and a suite of winter-time field measurements (including geophysical, shallow borehole, ground temperature, meteorologic, and topographic data) suggest that the slow migration of the GKSD are likely due to the presence of wind-shielding niveo-aeolian deposits, a seasonally frozen active layer, warm season rains, a regional aquifer beneath interdunes, and perched liquid water within dune uplands (Dinwiddie et al., 2012b). Observations of debris flows and gullies on lee slopes of the GKSD resulting from thaw of niveo-aeolian deposits, at a time when mean daily ground temperatures were greater than $12{ }^{\circ} \mathrm{C}$ below the thaw point shows the potential for sediment mobilization on dunes under conditions similar to those on Mars (Hooper et al., 2012). Demitroff et al. (2012) described the utility of the "Pine Barrens" region of New Jersey as a planetary analog for martian periglacial features, such as those associated with deep seasonal frost, permafrost, and mid-latitudinal, polycyclic climate change.

Research into cryo-aeolian processes on Mars centered on thermal inertia investigations. The anomalously low thermal inertia data of the vast Olympia Undae northern dune fields $(\sim 120$ $240^{\circ} \mathrm{E}$ and $\sim 78-83^{\circ} \mathrm{N}$ ) were previously modeled with strata of basaltic sand over ground ice (Putzig et al., 2010; Titus et al., 2011). Sensitivity testing of this model indicates that thermal inertias are not greatly affected by the wide distribution of dune slope orientations or lateral heterogeneity, such that the two-layer model remains robust (Putzig et al., 2012). In Kaiser Crater $\left(340.9^{\circ} \mathrm{E}\right.$, $46.6^{\circ} \mathrm{S}$ ), seasonal variations in thermal inertia are observed, consistent with temperature-dependent conductivity, storage of heat from ground ice, and/or dune induration (Cornwall et al., 2012). If seasonal induration is borne out in further research, it could argue for niveo-aeolian deposits within the dunes. In a related ground-truth study, in situ temperature observations and derived thermal diffusivity values from the Grand Falls dune field near Leupp, AZ, suggest layering, inferred to be most likely caused by sand densification with depth (Titus and Cushing, 2012). Improved spatial resolution of epithermal neutron-derived maps of north polar seasonal $\mathrm{CO}_{2}$ frost on Mars show spatial variations of $\mathrm{CO}_{2}$ frost associated with dunes and hints at a role for buried $\mathrm{H}_{2} \mathrm{O}$ in controlling the occurrence of $\mathrm{CO}_{2}$ (Teodoro et al., 2012).

Morphological studies of martian terrain also provided insight into cryo-aeolian processes. In a geomorphologic study of the spiral troughs on Mars' north polar ice cap, observations of katabatic processes were used to infer rates of trough migration, which primarily occur during late spring and the first days of northern summer (Smith and Holt, 2012). Dune crest data from the Hyperborea Undae in Chasma Boreale $\left(463.7^{\circ} \mathrm{E}, 80.0^{\circ} \mathrm{N}\right)$ are consistent with current local springtime wind conditions as modeled at the mesoscale (Christian et al., 2012). In the south polar region, as a supplement to the equatorial Mars Global Digital Dune Database, Hayward et al. (2012) created a map of $\sim 750$ dune fields, showing that winds predicted by a global climate model do not agree well with winds inferred from slipface orientations, a finding consistent with that of Newman et al. (2012). A study of mass movement morphologies on martian dunes (including leveed channels, dendritic channels, dune gullies, slumps, streaks, and alcoves) is an early attempt to correlate these morphologies with modes and causes of transportation, which appear to be hemisphere-dependent (Horgan et al., 2012b).

\subsection{Recent bedform migration on Mars}

Due to the abundance of high-resolution images and increased temporal baseline between images over the past five Mars years (roughly the last terrestrial decade), great progress has been made with Mars bedform detection and monitoring. Authors in this session described campaigns using recent data from the High Resolution Imaging Science Experiment (HiRISE), with a pixel scale as small as $25 \mathrm{~cm}$, showing unambiguous cases of dune and ripple migrations (Silvestro et al., 2010a; Chojnacki et al., 2011; Bridges et al., 2012b). Adding to evidence reported at the last dune workshop (Silvestro et al., 2010b; Chojnacki et al., 2010) for isolated aeolian activity, the geographic and volumetric extents of bedform activity are now more clearly constrained. Geissler et al. (2012) displayed global maps of dune movement detections vs. nondetections and discussed preliminary analyses that suggested bedform activity is greatest at the northern polar region, equatorial latitudes, and at lower elevations. Although current dune activity 
is found consistently occurring in the high northern latitudes, debate exists on the relative contributions for dune movement from aeolian vs. ice-related processes (i.e., destabilization or mass-wasting as a result of water and $\mathrm{CO}_{2}$ ice interactions) (Hansen et al., 2011; Horgan and Bell, 2012b; Horgan et al., 2012b). Additional occurrences of bedform activity in the martian tropics at Gale crater, the current landing site of the Mars Science Laboratory rover Curiosity, were described by Silvestro et al. (2012), boding well for future in situ analyses of an active martian dune field. Likewise, Chojnacki et al. (2012b) reported the first results from the Mars Exploration Rover Opportunity Pancam monitoring of Endeavour crater's "Greeley Dune Field". The method of computing volumetric sand fluxes using HiRISE-derived DTMs, for comparison with terrestrial examples, was provided by Ayoub et al. (2012). Nili Patera dune sand fluxes were estimated to be on the order of $\sim 2-5 \mathrm{~m}^{2} \mathrm{yr}^{-1}$ and are comparable with fluxes of slower dunes of Earth (Ayoub et al., 2012; Bridges et al., 2012b). Mattson et al. (2012) demonstrated recent advances in producing DTMs from HiRISE images that provide higher quality data with less human effort, which will make future analyses more robust. Bedform activity on Mars represents the first measured dune movement beyond terrestrial examples. Bedform activity on Venus (Kreslavsky and Bondarenko, 2012), Titan (Radebaugh et al., 2012), and Pluto (Ewing, 2012) was also discussed but remains unknown, although predictions and tests continue with ongoing missions to the latter two bodies.

\subsection{The planetary aeolian laboratory}

Experimental data are a critical part of understanding aeolian processes. For both terrestrial and perhaps especially extraterrestrial investigations, conducting experiments in a controlled setting where specific parameters can be isolated and varied under known circumstances provides valuable information about the mechanics and physics of aeolian sediment entrainment, transport and its erosive effects, and deposition. The extensive planetary wind tunnel work (e.g., see references in Zimbelman, 2012) attests to the vital contribution that experimental work makes to understanding extraterrestrial aeolian processes.

The Planetary Aeolian Laboratory (PAL) at the NASA Ames Research Center in Mountain View, CA, USA houses a low-pressure (Mars) tunnel and high-pressure (Titan) tunnel, which are available to researchers funded through the NASA Planetary Geology and Geophysics (PGG) program. The PAL also hosts a vortex generator, abrasion apparatus, and support equipment. However, these unique planetary facilities are aging and for this reason can be challenging to use. Workshop participants, led by Nathan Bridges (Johns Hopkins University Applied Physics Laboratory), discussed the state and future of these planetary aeolian facilities, summarizing their results with the following recommendations (in order of importance):

1. Do a cost-benefit analysis regarding the building of a new lowpressure (Mars) wind tunnel.

2. Maintain NASA funding for planetary wind tunnel if upgrades and dedicated management and support staff can be found.

3. Open PAL to NASA researchers outside of the PGG program.

4. Consider a business model that also supports international investigations.

It was noted that the current wind tunnel contract with NASA expires in 2015, so that action before that date is important. A letter with this information was sent to PAL PI Dave Williams (Arizona State University). Dr. Williams responded immediately by publishing an abstract at both the American Geophysical Union 2012 Fall Meeting and the Geological Society of America 2012
Annual Meeting \& Exposition that describes the PAL to the community. Additionally, Dr. Williams has drafted a response letter that acknowledges and addresses several of the above concerns, including upgrades to the PAL, making the facility more accessible to the community by preparing a guidebook for proposers, recommending broadening funding opportunities to include two additional NASA programs (the Mars Fundamental Research and Outer Planets Research Programs), and requesting future funding for a dedicated research technician at the Arizona State University facility.

\subsection{Field trip: great falls dune field and vicinity}

A post-workshop field trip was taken to the Grand Falls dune field, a small, active dune field about $50 \mathrm{~km}$ northeast of Flagstaff. The dune field, analogous to Mars dune fields because of its basalt component, is located within the San Francisco volcanic field, which has produced more than 600 volcanoes. At the first stop, overlooking Grand Falls and the Little Colorado River, Lee Amoroso (USGS, Flagstaff) led a discussion about the potential sources of the quartz and basalt sand that make up the Grand Falls dune field. At the second stop, Rian Bogle and John Vogel (USGS, Flagstaff) discussed their work at the site, including monitoring dune migration rates and an ongoing experiment in dune immobilization. Participants were given time to explore the dune field and photograph the interplay of quartz and basalt in the dunes and ripples. The third stop was the site of a dry lake bed that is the source of intense dust storms seen in satellite imagery. The final stop was about $20 \mathrm{~km}$ south of the dune field at the site of a basaltic sand sheet originating from a wash.

\section{Future approaches, major outcomes of workshop}

The advantage to holding regular meetings within a small community is that it is possible to watch the progression of individual projects and to observe the influence of the community's feedback. For example, the 2010 International Planetary Dunes Workshop involved a field trip to the Great Sand Dunes National Park in Colorado, including a stop at a mysterious landform named the "Crestone Crater". Debate among workshop participants about the feature's origin (aeolian, impact, or other) inspired undergraduate students to perform field work with geophysical techniques, including measurement of gravity and magnetic anomalies, as well as electrical resistivity (Cox et al., 2012). The preliminary results were consistent with an impact origin and inconsistent with an aeolian origin, in contrast to previous work.

It is also possible to observe progress made by the community as a whole. During the first and second International Planetary Dunes Workshops, participants identified several priorities for future planetary dune research (Titus et al., 2008, 2010). In this workshop, it became clear that significant progress has been made on most of those priorities. Major scientific questions that arose during the workshop are addressed by Titus et al. (2012). In addition, the workshop provides a forum for the planetary aeolian

Table 2

Number of oral and poster presentations by planetary body.

\begin{tabular}{lccc}
\hline Topic & \# Oral & \# Poster & \# Total \\
\hline Venus & 1 & 1 & 2 \\
Earth & 8 & 7 & 15 \\
Mars & 12 & 11 & 23 \\
Titan & 2 & 3 & 5 \\
Multiple worlds & 3 & 1 & 4 \\
Other & 2 & 1 & 3 \\
Total & 28 & 24 & 52 \\
\hline
\end{tabular}


community to discuss and make decisions regarding issues that impact the entire group (e.g., addressing the future of the PAL). Finally, the field trips serve as an opportunity for planetary researchers, who are often restricted to a laboratory or the intangible realm of models and spacecraft data, to experience aeolian processes in situ.Major themes of this workshop include:

1. Technological advancement. The introduction or refinement of several new computational methods and data analysis techniques made a significant mark in all sessions of the workshop. These advancements include (but are not limited to): automatic detection of bedforms (Bandiera et al., 2012) and their crestlines, production of three dimensional models of field sites produced from digital imagery, computational fluid dynamic modeling of airflow in planetary atmospheres at an unprecedented scale $(\sim 1 \mathrm{~m})$, construction of digital terrain models of planetary surfaces at a similarly unprecedented scale $(\sim 1 \mathrm{~m})$, application of a terrestrial atmospheric model over a time span of decades to recreate historical events influencing aeolian processes, and development of a new version of the NASA Planetary Data System archive (Neakrase et al., 2012).

2. Novel field methods. The use of inexpensive, "off-the-shelf" instruments, have been used in the field to improve measurements. In particular, the use of time-lapse cameras and kites to provide (respectively) improved temporal and spatial perspective on bedform morphodynamics was unexpectedly illuminating

3. Progress on research priorities. Much of the presented work can be described as progress towards the "future research approaches" as outlined during the Second International Planetary Dunes Workshop (Titus et al., 2010; Fenton et al., 2010). For example, the boundary conditions that control dune patterns are being identified on Titan and Mars (priority 1 and 3 ). Substantial progress has also been made on identifying active dunes and determining migration rates on Mars (priority 9 ). Studies of terrestrial analogs are being used to better understand the influence of precipitation and ground ice on bedform morphology and dynamics, and continued study of TAR analogs provides additional constraints on their nature and behavior (priorities 11 and 13).

Some areas of study previously considered research priorities were not directly addressed during the workshop, but these topics still remain of great interest to the community. Only one presentation discussed laboratory study of bedform evolution, and no work was presented on laboratory studies of particle transport. It is hoped that with planned updates to the PAL, future work on particle entrainment in planetary environments will become more commonplace. Similarly, no updates to the discussion of mineralogical maturity that began in the 2010 International Planetary Dunes Workshop were presented. Finally, no discussion occurred on developing or applying absolute dating methods of sediment to planetary environments. These avenues of research merit further attention by the planetary aeolian community.

It is of interest to note the distribution of presentations by planetary body. Mars has been the target of numerous spacecraft; unsurprisingly, a correspondingly high proportion of presentations also focused on Mars ( $44 \%$, see Table 2$)$. However, there were a substantial number of presentations on terrestrial aeolian research, consisting of both analog field studies (looking for planetary explanations on Earth) and those that discussed only Earth landforms and processes (looking for similarities and applications elsewhere in the Solar System). With a continuing but tantalizingly low influx of data from the spacecraft Cassini, Titan remains a subject of inquiry. Finally, the surfaces of Venus, Pluto, and Triton suffer from a dearth of data regarding aeolian systems, but they are objects of significant interest to the planetary community. In particular, the flyby of New Horizons past Pluto in 2015 is eagerly anticipated, and may well provide insight on aeolian environments even more exotic than those previously studied.

\section{Conclusions}

The Third International Planetary Dunes Workshop was a productive successor in the ongoing series of Planetary Dunes Workshops. Continued small meetings of aeolian researchers from varied sub-disciplines provide a forum to further the goals of planetary aeolian science as a whole, as demonstrated by the community's mobilization to maintain the Planetary Aeolian Laboratory. In addition, the influx of new participants has provided fresh ideas, techniques, and perspectives that spur new collaborations. The journal Icarus has recently accepted a proposal for a special issue containing publications of papers presented at the workshop. Plans for a fourth workshop in 2014, tentatively to be held in central Idaho, are underway.

\section{Acknowledgements}

The authors would like to thank Dave Williams for a quick response to the planetary aeolian community and cooperation in preparation of the manuscript. In addition, we thank an anonymous reviewer for suggestions that improved the manuscript. Finally, we thank the Lunar and Planetary Institute, especially Ingrid Dudley and Linda Tanner, for helping to organize the meeting.

\section{References}

Ayoub, F., Bridges, N.T., Avouac, J.-P., 2012. Measurings and flux and its seasonality from a time series of HiRISE images. In: Third International Planetary Dunes Workshop: Remote Sensing and Image Analysis of Planetary Dunes. Flagstaff, Arizona, abst. \#7026. <http://www.lpi.usra.edu/meetings/dunes2012/pdf/ 7026.pdf>.

Bachman, S.R., Titus, T.N., Edwards, C.S., 2012. Mineral analysis of Martian dunes: constraining possible sediment source. In: Third International Planetary Dunes Workshop: Remote Sensing and Image Analysis of Planetary Dunes. Flagstaff, Arizona, abst. \#7032. <http://www.lpi.usra.edu/meetings/dunes2012/pdf/ 7032.pdf $>$.

Bandeira, L., Pina, P., Marques, J.S., Saraiva, J., 2012. Supervised learning strategies for automated detection of martian dune fields. In: Third International Planetary Dunes Workshop: Remote Sensing and Image Analysis of Planetary Dunes. Flagstaff, Arizona, abst. \#7039. <http://www.lpi.usra.edu/meetings/ dunes2012/pdf/7039.pdf>.

Berman, D.C., Balme, M.R., Rafkin, S.C.R., Zimbelman, J.R., 2011. Transverse Aeolian Ridges (TARs) on Mars II: distributions, orientations, and ages. Icarus 213 (1) 116-130. http://dx.doi.org/10.1016/j.icarus.2011.02.014.

Berman, D.C., Balme, M.R., Michaels, T.I., 2012. Investigations of transverse aeolian ridges on Mars. In: Third International Planetary Dunes Workshop: Remote Sensing and Image Analysis of Planetary Dunes. Flagstaff, Arizona, abst. \#7025. <http://www.lpi.usra.edu/meetings/dunes2012/pdf/7025.pdf>

Bishop, M.A., 2012. The relationships between dune-dune interactions, boundary conditions and dune field development, Al Liwa Basin, the Empty Quarter. In: Third International Planetary Dunes Workshop: Remote Sensing and Image Analysis of Planetary Dunes. Flagstaff, Arizona, abst. \#7011. <http:// www.lpi.usra.edu/meetings/dunes2012/pdf/7011.pdf >

Bridges, N.T., de Silva, S.L., Zimbelman, J.R., Lorenz, R.D., 2012a. Formation conditions for coarse-grained megaripples on Earth and Mars: lessons from the Argentinean Puna and wind tunnel experiments. In: Third International Planetary Dunes Workshop: Remote Sensing and Image Analysis of Planetary Dunes. Flagstaff, Arizona, abst. \#7010. <http://www.lpi.usra.edu/meetings/ dunes2012/pdf/7010.pdf>.

Bridges, N.T., Ayoub, F., Avouac, J.-P., Leprince, S., Lucas, A., Mattson, S., 2012b. Earth-like sand fluxes on Mars. Nature 485, 339-342.

Burr, D.M., Zimbelman, J.R. de Silva, S.L., Bridges, N.T., Chojnacki, M., Qualls, F.B. 2012. Testing the volcaniclastic hypothesis for martian dune sediments: the Medusae Fosse Formation, Mars, and Andean ignimbrites, Earth. In: Third International Planetary Dunes Workshop: Remote Sensing and Image Analysis of Planetary Dunes. Flagstaff, Arizona, abst. \#7024. <http://www.lpi.usra.edu/ meetings/dunes2012/pdf/7024.pdf>.

Chojnacki, M., Burr, D.M., Moersch, J.E., 2010. Evidence of bed form deflation, modification and transport at Endeavour crater, Meridiani Planum, Mars, from orbital observations. In: Second International Planetary Dunes Workshop: Planetary Analogs - Integrating Models, Remote Sensing, and Field Data. Alamosa, Colorado, abst. \#2028. <http://www.lpi.usra.edu/meetings/ dunes2010/pdf/2028.pdf>. 
Chojnacki, M., Burr, D.M., Moersch, J.E., Michaels, T.I., 2011. Orbital observations of contemporary dune activity in Endeavor crater, Meridiani Planum, Mars. J. Geophys. Res. 116, E00F19. http://dx.doi.org/10.1029/2010JE003675.

Chojnacki, M., Moersch, J.E., Burr, D.M., Wray, J.J., 2012a. Potential sediment sources and pathways in Valles Marineris dune fields: Implications for martian aeolian systems. In: Third International Planetary Dunes Workshop: Remote Sensing and Image Analysis of Planetary Dunes. Flagstaff, Arizona, abst. \#7040. <http:// www.lpi.usra.edu/meetings/dunes2012/pdf/7040.pdf>

Chojnacki, M., Johnson, J.R., Moersch, J.E., Bell, J.F. III., 2012b. Surface and orbital monitoring of the "Greeley Dune Field" in Endeavour crater, Meridiani Planum, Mars. In: Third International Planetary Dunes Workshop: Remote Sensing and Image Analysis of Planetary Dunes. Flagstaff, Arizona, abst. \#7038. <http:// www.lpi.usra.edu/meetings/dunes2012/pdf/7038.pdf>

Christian, S., Kocurek, G., Spiga, A., 2012. Combining dune field analyss with wind model results to understand recent evolution of Hyperboreae Undae, Mars. In: Third International Planetary Dunes Workshop: Remote Sensing and Image Analysis of Planetary Dunes. Flagstaff, Arizona, abst. \#7012. <http:// www.lpi.usra.edu/meetings/dunes2012/pdf/7012.pdf>

Cornwall, C., Wood, S., Johnson, M., 2012. Possible seasonal induration of southern mid-latitude dune fields on Mars. In: Third International Planetary Dunes Workshop: Remote Sensing and Image Analysis of Planetary Dunes. Flagstaff, Arizona, abst. \#7055. <http://www.lpi.usra.edu/meetings/dunes2012/pdf/ 7055.pdf >.

Cox, C., Isherwood, R., Reitz, A., Krahenbuhl, R., Andrews-Hanna, J.C., Valdez, A., 2012. Geophysical analysis of the Crestone "Crater", Great Sand Dunes National Park, Colorado. In: Third International Planetary Dunes Workshop: Remote Sensing and Image Analysis of Planetary Dunes. Flagstaff, Arizona, abst. \#7042. <http://www.lpi.usra.edu/meetings/dunes2012/pdf/7042.pdf>

de Silva, S.L., Bridges, N.T., Zimbelman, J.R., Spagnuolo, M.G., Burr, D.M., Scheidt, S., Ortiz, A. 2012. Investigating the coarsest gravel ripples on Earth-Field relationships, sedimentological character and implications for Mars. In: Third International Planetary Dunes Workshop: Remote Sensing and Image Analysis of Planetary Dunes. Flagstaff, Arizona, abst. \#7035. <http://www.lpi.usra.edu/ meetings/dunes2012/pdf/7035.pdf>

Demitroff, M. Cicali, M., Smith, J., Demitroff, A.N., 2012. Ancient eolian landforms and features from a terrestrial mid-latitude periglacial environment. In: Third International Planetary Dunes Workshop: Remote Sensing and Image Analysis of Planetary Dunes. Flagstaff, Arizona, abst. \#7041. <http://www.lpi.usra.edu/ meetings/dunes2012/pdf/7041.pdf>.

Dinwiddie, C.L., Michaels, T.I., Hooper, D.M., Stillman, D.E., 2012a. Environmental conditions and meteorologic context for modification of the Great Kobuk Sand Dunes, northwestern Alaska. In: Third International Planetary Dunes Workshop: Remote Sensing and Image Analysis of Planetary Dunes. Flagstaff, Arizona, abst. \#7033. <http://www.lpi.usra.edu/meetings/dunes2012/pdf/ 7033.pdf>.

Dinwiddie, C.L., McGinnis, R.N., Stillman, D.E., Bjella, K.L., Grimm, R.E., 2012b. Internal sedimentary structure and aqueous-phase distribution of the Great Kobuk Sand Dunes, northwestern Alaska: Insights from an arctic aeolian analog site. In: Third International Planetary Dunes Workshop: Remote Sensing and Image Analysis of Planetary Dunes. Flagstaff, Arizona, abst. \#7034. <http:// www.lpi.usra.edu/meetings/dunes2012/pdf/7034.pdf>

Draut, A.E., Rubin, D.M., 2012. Interactions between subaqueous and aeolian sedimentary systems. In: Third International Planetary Dunes Workshop: Remote Sensing and Image Analysis of Planetary Dunes. Flagstaff, Arizona, abst. \#7004. <http://www.lpi.usra.edu/meetings/dunes2012/pdf/7004.pdf>.

Edgar, L.A., 2012. Reconstruction of eolian bedforms and paleocurrents at Meridiani Planum, Mars. In: Third International Planetary Dunes Workshop: Remote Sensing and Image Analysis of Planetary Dunes. Flagstaff, Arizona, abst. \#7027. <http://www.lpi.usra.edu/meetings/dunes2012/pdf/7027.pdf>

Edgett, K., 1997. Aeolian dunes as evidence for explosive volcanism in the Tharsis region of Mars. Icarus 130 (1), 96-114. http://dx.doi.org/10.1006/ icar.1997.5806

Edgett, K.S., Lancaster, N., 1993. Volcaniclastic aeolian dunes: terrestrial examples and application to Martian sands. J. Arid Environ. 25, 271-297. http:// dx.doi.org/10.1006/jare.1993.1061.

Ewing, R.C., 2012. Source-to-sink: Comparison of boundary conditions for planetary aeolian systems. In: Third International Planetary Dunes Workshop: Remote Sensing and Image Analysis of Planetary Dunes. Flagstaff, Arizona, abst. \#7022. $<$ http://www.lpi.usra.edu/meetings/dunes2012/pdf/7022.pdf>

Fenton, L.K., Beyer, R.A., 2012. Reconstructing the formative winds of a dune field in Ganges Chasma, Mars, by bootstrapping with the rule of maximum gross bedform-normal transport. In: Third International Planetary Dunes Workshop: Remote Sensing and Image Analysis of Planetary Dunes. Flagstaff, Arizona, abst. \#7028. <http://www.lpi.usra.edu/meetings/dunes2012/pdf/ 7028.pdf>.

Fenton, L.K., Bishop, M.A., Bourke, M.C., Bristow, C.S., Hayward, R.K., Horgan, B.H., Lancaster, N., Michaels, T.I., Tirsch, D., Titus, T.N., Valdez, A., 2010. Summary of the second international planetary dunes workshop: planetary analogsintegrating models, remote sensing, and field data, Alamosa, Colorado, USA, May 18-21, 2010. Aeolian Res. 2 (2-3), 173-178. http://dx.doi.org/10.1016/ j.aeolia.2010.09.001.

Geissler, P.E., Banks, M.E., Bridges, N.T., Silvestro, S., the HiRISE Science Team, 2012. HiRISE observations of sand dune motion on Mars: emerging global trends. In: Third International Planetary Dunes Workshop: Remote Sensing and Image Analysis of Planetary Dunes. Flagstaff, Arizona, abst. \#7053. <http:// www.lpi.usra.edu/meetings/dunes2012/pdf/7053.pdf>.
Greeley, R., Bender, K.C., Saunders, R.S., Schubert, G., Weitz, C.M., 1997. Aeolian Processes and Features on Venus. Venus II: Geology, Geophysics, Atmosphere, and Solar Wind Environment. University of Arizona Press, pp. 547-589.

Hansen, C.J., Bourke, M., Bridges, N.T., Byrne, S., Colon, C., Diniega, S., Dundas, C., Herkenhoff, K., McEwen, A., Mellon, M., Portyankina, G., Thomas, N., 2011. Seasonal erosion and restoration of Mars' northern polar dunes. Science 331 (6017), 575-578. http://dx.doi.org/10.1126/science.1197636.

Hayes, A.G., Ewing, R.C., Lucas, A., McCormick, C., Troy, S., Ballard, C., 2012. Determining timescales of the dune forming winds on Titan. In: Third International Planetary Dunes Workshop: Remote Sensing and Image Analysis of Planetary Dunes. Flagstaff, Arizona, abst. \#7057. <http://www.lpi.usra.edu/ meetings/dunes2012/pdf/7057.pdf>.

Hayward, R.K., Fenton, L.K., Titus, T.N., 2012. South polar region of Mars Global Digital Dune Database: wind direction analysis and sand volume estimates in MC-30. In: Third International Planetary Dunes Workshop: Remote Sensing and Image Analysis of Planetary Dunes. Flagstaff, Arizona, abst. \#7021. <http:// www.lpi.usra.edu/meetings/dunes2012/pdf/7021.pdf>.

Hooper, D.M., Dinwiddie, C.L., McGinnis, R.N., 2012. Meltwater-induced debris flows on cold-climate aeolian dunes and the implications for analogous processes on Mars. In: Third International Planetary Dunes Workshop: Remote Sensing and Image Analysis of Planetary Dunes. Flagstaff, Arizona, abst. \#7046. <http:// www.lpi.usra.edu/meetings/dunes2012/pdf/7046.pdf>

Horgan, B., Bell III, J.F., 2012a. Widespread weathered glass on the surface of Mars. Geology 40, 391-394. http://dx.doi.org/10.1130/G32755.1.

Horgan, B., Bell III, J.F., 2012b. Seasonally active slipface avalanches in the north polar sand sea of Mars: evidence for a wind-related origin. Geophys. Res. Lett. 39 (9), L09201. http://dx.doi.org/10.1029/2012GL051329.

Horgan, B., Clarke, D., Bell, J.F. III., 2012a. Evidence for glass-rich pyroclastics in martian dunes. In: Third International Planetary Dunes Workshop: Remote Sensing and Image Analysis of Planetary Dunes. Flagstaff, Arizona, abst. \#7050. <http://www.lpi.usra.edu/meetings/dunes2012/pdf/7050.pdf>.

Horgan, B., Fenton, L., Christensen, P., 2012b. Comparing active modes of mass movement on martian dunes. In: Third International Planetary Dunes Workshop: Remote Sensing and Image Analysis of Planetary Dunes. Flagstaff, Arizona, abst. \#7052. <http://www.lpi.usra.edu/meetings/dunes2012/pdf/ 7052.pdf>.

Jackson, D.W.T., Smyth, T.A.G., Bourke, M.C., Beyers, J.H. M., 2012. High resolution computational fluid dynamic modelling of airflow over dunes in Proctor crater, Mars. In: Third International Planetary Dunes Workshop: Remote Sensing and Image Analysis of Planetary Dunes. Flagstaff, Arizona, abst. \#7018. <http:// www.lpi.usra.edu/meetings/dunes2012/pdf/7018.pdf>

Kerber, L., Head, J.W., Forget, F., 2012. Aeolian features in the Medusa Fossae Formation: a HiRISE survey. In: Third International Planetary Dunes Workshop: Remote Sensing and Image Analysis of Planetary Dunes. Flagstaff, Arizona, abst. \#7016. <http://www.lpi.usra.edu/meetings/dunes2012/pdf/7016.pdf>.

Kok, J.F., 2010. Difference in the wind speeds required for initiation versus continuation of sand transport on mars: implications for dunes and dust storms. Phys. Rev. Lett. 104 (7), 1-4. http://dx.doi.org/10.1103/ PhysRevLett.104.074502.

Kreslavsky, M.A., Bondarenko, N.V., 2012. Aeolian transport and aeolian deposits on Venus: an overview of remote sensing observations. In: Third International Planetary Dunes Workshop: Remote Sensing and Image Analysis of Planetary Dunes. Flagstaff, Arizona, abst. \#7008. <http://www.lpi.usra.edu/meetings/ dunes2012/pdf/7008.pdf>.

Le Gall, A., Rodriguez, S., Garcia, A., Radebaugh, J., Lorenz, R.D., Lopes, R.M.C., Hayes, A., Reffet, E., 2012. Titan's dunes by the numbers. In: Third International Planetary Dunes Workshop: Remote Sensing and Image Analysis of Planetary Dunes. Flagstaff, Arizona, abst. \#7037. <http://www.lpi.usra.edu/meetings/ dunes2012/pdf/7037.pdf>.

Lorenz, R.D., 2012. Timescales of dune obliteration and repair on Titan. In: Third International Planetary Dunes Workshop: Remote Sensing and Image Analysis of Planetary Dunes. Flagstaff, Arizona, abst. \#7014. <http://www.lpi.usra.edu/ meetings/dunes2012/pdf/7014.pdf>.

Lorenz, R.D., Valdez, A., 2012. Observations of niveo-aeolian activity at Great Sand Dunes National Park and Preserver (GSDNPP). In: Third International Planetary Dunes Workshop: Remote Sensing and Image Analysis of Planetary Dunes. Flagstaff, Arizona, abst. \#7013. <http://www.lpi.usra.edu/meetings/dunes2012/ pdf/7013.pdf>.

Mattson, S., Bridges, N.T., Kirk, R.L., Howington-Kraus, E., Mogk, N., Ojha, L., 2012. Studying martian dune change with HiRISE DTMs and orthoimages. In: Third International Planetary Dunes Workshop: Remote Sensing and Image Analysis of Planetary Dunes. Flagstaff, Arizona, abst. \#7030. <http://www.lpi.usra.edu/ meetings/dunes2012/pdf/7030.pdf>.

Michaels, T.I., 2012. Towards a better understanding of longer-term aeolian processes on Earth via dynamical downscaling. In: Third International Planetary Dunes Workshop: Remote Sensing and Image Analysis of Planetary Dunes. Flagstaff, Arizona, abst. \#7045. <http://www.lpi.usra.edu/meetings/ dunes2012/pdf/7045.pdf>.

Montgomery, D.R., Bandfield, J.L., Becker, S.K., 2012. Periodic bedrock ridges on Mars. J. Geophys. Res. 117 (E3), 1-12. http://dx.doi.org/10.1029/ 2011JE003970.

Neakrase, L.D.V., Huber, L., Rees, S., Roybal, M., Beebe, R., Crichton, D.J., Hughes, J.S., Gordon, M.K., Mafi, J., 2012. The PDS4 archive: new structure, new possibilities. In: Third International Planetary Dunes Workshop: Remote Sensing and Image Analysis of Planetary Dunes. Flagstaff, Arizona, abst. \#7049. <http:// www.lpi.usra.edu/meetings/dunes2012/pdf/7049.pdf>. 
Newman, C.E., Richardson, M.I., Lancaster, N., Rubin, D.M., 2012. General circulation mod predictions of dunes on Mars and Titan using planetWRF. In: Third International Planetary Dunes Workshop: Remote Sensing and Image Analysis of Planetary Dunes. Flagstaff, Arizona, abst. \#7009. <http://www.lpi.usra.edu/ meetings/dunes2012/pdf/7009.pdf $>$.

Putzig, N.E., Mellon, M.T., Herkenhoff, K.E., Phillips, R.J., Davis, B.J., Ewer, K.J., 2010. Thermal anomaly in Martian north polar erg likely due to near-surface ice. In: Second International Planetary Dunes Workshop: Planetary Analogs Integrating Models, Remote Sensing, and Field Data. Alamosa, Colorado, abst. \#2037. <http://www.lpi.usra.edu/meetings/dunes2012/pdf/7024.pdf>.

Putzig, N.E., Bowers, L.M., Mellon, M.T., Herkenhoff, K.E., Phillips, R.J., 2012. Thermal effects of physical heterogeneity in Olympia Undae. In: Third International Planetary Dunes Workshop: Remote Sensing and Image Analysis of Planetary Dunes. Flagstaff, Arizona, abst. \#7054. <http://www.lpi.usra.edu/meetings/ dunes2012/pdf/7054.pdf>.

Radebaugh, J., Lorenz, R.D., Le Gall, A., 2012. Dunes on Titan at the beginning of the Cassini solstice mission. In: Third International Planetary Dunes Workshop: Remote Sensing and Image Analysis of Planetary Dunes. Flagstaff, Arizona, abst. \#7031. <http://www.lpi.usra.edu/meetings/dunes2012/pdf/7031.pdf>.

Reffet, E., Courrech du Pont, S., Hersen, P., Douady, S., 2012. Evolution of laboratory dunefield analogs, 2012. In: Third International Planetary Dunes Workshop: Remote Sensing and Image Analysis of Planetary Dunes. Flagstaff, Arizona, abst. \#7043. <http://www.lpi.usra.edu/meetings/dunes2012/pdf/7043.pdf>.

Rodriguez, S., Le Mouélic, S., Barnes, J.W., Hirtzig, M., Rannou, P., Sotin, C., Brown, R.H., Bow, J., Vixie, G., Cornet, T., Bourgeois, O., Narteau, C., Courrech du Pont, S. Le Gall, A., Reffet, E., Griffith, C.A., Jaumann, R., Stephan, K., Buratti, B. J., Clark, R.N., Baines, K.H., Nicholson, P.D., 2012. Equinoctial atmospheric activity over Titan dune fields revealed by Cassini/VIMS. In: Third International Planetary Dunes Workshop: Remote Sensing and Image Analysis of Planetary Dunes. Flagstaff, Arizona, abst. \#7029. <http://www.lpi.usra.edu/meetings/dunes2012/ pdf/7029.pdf $>$.

Rubin, D.M., 2012. A unifying model for planform straightness of ripples and dunes in air and water. In: Third International Planetary Dunes Workshop: Remote Sensing and Image Analysis of Planetary Dunes. Flagstaff, Arizona, abst. \#7020. <http://www.lpi.usra.edu/meetings/dunes2012/pdf/7020.pdf>.

Rubin, D.M., Hunter, R.E., 1987a. Bedform alignment in directionally varying flows. Science (New York, NY) 237 (4812), 276-278. http://dx.doi.org/10.1126/ science.237.4812.276.

Rubin, D.M., Hunter, R.E., 1987b. Field guide to sedimentary structures in the Navajo and Entrada Sandstones in southern Utah and Northern Arizona. In: Davis, G.H. Vanden Dolder, E.M. (Eds.), Geologic Diversity of Arizona and its MarginsExcursions to Choice Areas: Geological Society of America 100th Annua Meeting, Phoenix, Arizona, Guidebook. Geological Survey Branch Special Paper, v. 5, Arizona Bureau of Geology and Mineral Technology, pp. 126-139.

Scheidt, S.P., 2012. Sand transport pathways of dark dunes in the Sperrgebiet: Sand composition and dune migration rates from ASTER data. In: Third International Planetary Dunes Workshop: Remote Sensing and Image Analysis of Planetary Dunes. Flagstaff, Arizona, abst. \#7051. <http://www.lpi.usra.edu/meetings/ dunes2012/pdf/7051.pdf>.

Silvestro, S., Fenton, L.K., Vaz, D.A., Bridges, N.T., Ori, G.G., 2010a. Ripple migration and dune activity on Mars: evidence for dynamic processes. Geophys. Res. Lett. 37. http://dx.doi.org/10.1029/2010GL044743.

Silvestro, S., Fenton, L.K., Vaz, D.A., Ori, G.G., 2010b. Ripple migration on active dunes in Nili Patera (Mars). In: Second International Planetary Dunes Workshop: Planetary Analogs - Integrating Models, Remote Sensing, and Field Data. Alamosa, Colorado, abst. \#2003. <http://www.lpi.usra.edu/ meetings/dunes2010/pdf/2003.pdf>.

Silvestro, S., Vaz, D.A., Rossi, A.P., Flahaut, J., Fenton, L.K., Ewing, R., Geissler, P.E., 2012. Active aeolian processes along Curiosity's traverse. In: Third International Planetary Dunes Workshop: Remote Sensing and Image Analysis of Planetary Dunes. Flagstaff, Arizona, abst. \#7036. <http://www.lpi.usra.edu/meetings/ dunes2012/pdf/7036.pdf>.

Smith, I.B., Holt, J.W., 2012. The northern spiral troughs of Mars as cyclic steps: a framework for using observations of active processes to calculate migration and accumulation rates on the NPLD. In: Third International Planetary Dunes Workshop: Remote Sensing and Image Analysis of Planetary Dunes. Flagstaff, Arizona, abst. \#7047. <http://www.lpi.usra.edu/meetings/dunes2012/pdf/ 7047.pdf $>$.

Teodoro, L.F.A., Feldman, W.C., Bourke, M., 2012. Variations in north polar seasonal $\mathrm{CO}_{2}$ ice: Improved distribution maps using pixon image reconstruction. In: Third International Planetary Dunes Workshop: Remote Sensing and Image Analysis of Planetary Dunes. Flagstaff, Arizona, abst. \#7056. <http:// www.lpi.usra.edu/meetings/dunes2012/pdf/7056.pdf>.

Tirsch, D., Jaumann, R., 2012. On the sources of dark dune sands on Mars. In: Third International Planetary Dunes Workshop: Remote Sensing and Image Analysis of Planetary Dunes. Flagstaff, Arizona, abst. \#7017. <http://www.lpi.usra.edu/ meetings/dunes2012/pdf/7017.pdf>.

Tirsch, D., Jaumann, R., Pacifici, A., Poulet, F., 2011. Dark aeolian sediments in Martian craters: composition and sources. J. Geophys. Res. 116, E03002. http:// dx.doi.org/10.1029/2009je003562.

Tirsch, D., Craddock, R.A., Platz, T., Maturilli, A., Helbert, J., Jaumann, R., 2012 Spectral and petrologic analyses of basaltic sands in Ka'u Desert (Hawaii) implications for the dark dunes on Mars. Earth Surf. Process. Landf. 37 (4), 434 448. http://dx.doi.org/10.1002/esp. 2266.

Titus, T.N., Cushing, G.E., 2012. Thermal diffusivity experiment at the Grand Falls dune field. In: Third International Planetary Dunes Workshop: Remote Sensing and Image Analysis of Planetary Dunes. Flagstaff, Arizona, abst. \#7044. <http:// www.lpi.usra.edu/meetings/dunes2012/pdf/7044.pdf>.

Titus, T.N., Lancaster, N., Hayward, R.K., Fenton, L.K., Bourke, M.C., 2008. Priorities for future research on planetary dunes. Eos, Trans. Am. Geophys. Union 89 (45) 447-448.

Titus, T.N., Hayward, R.K., Bourke, M.C., 2010. Interdisciplinary research produces results in the understanding of planetary dunes. Eos, Trans. Am. Geophys. Union 91 (32), 281.

Titus, T.N., Cushing, G.E., Prettyman, T.H., 2011. Thermal emission spectrometer estimates of the Mars north polar ice table depth and thermal inertia. In: Fifth Mars Polar Science Conference, Fairbanks, Alaska, abst. \#6055. <http:// www.lpi.usra.edu/meetings/polar2011/pdf/6055.pdf >.

Titus, T.N., Hayward, R.K., Dinwiddie, C., 2012. Interdisciplinary research produces results in the understanding of planetary dunes. Eos, Trans. Am. Geophys. Union 93 (38), 367 (September 18 issue).

Valdez, A., 2012. Observations on dune behavior at Great Sand Dunes National Park, Colorado. In: Third International Planetary Dunes Workshop: Remote Sensing and Image Analysis of Planetary Dunes. Flagstaff, Arizona, abst. \#7048. <http:// www.lpi.usra.edu/meetings/dunes2012/pdf/7048.pdf>.

Vaz, D.A., Silvestro, S., 2012. An object based approach for the mapping and characterization of Mars ripples. In: Third International Planetary Dunes Workshop: Remote Sensing and Image Analysis of Planetary Dunes. Flagstaff Arizona, abst. \#7019. <http://www.lpi.usra.edu/meetings/dunes2012/pdf/ 7019.pdf $>$.

Yizhaq, H., Kok, J.F., 2012. Basaltic sand ripples in Eagle crater as indirect evidence for the hysteresis effect in Martian saltation. In: Third International Planetary Dunes Workshop: Remote Sensing and Image Analysis of Planetary Dunes. Flagstaff, Arizona, abst. \#7023. <http://www.lpi.usra.edu/meetings/dunes2012/ pdf/7023.pdf>

Zimbelman, J.R., 2012. "The answer is blowin' in the wind": the remarkable aeolian career of Ronald Greeley. In: Third International Planetary Dunes Workshop: Remote Sensing and Image Analysis of Planetary Dunes. Flagstaff, Arizona, abst. \#7002. <http://www.lpi.usra.edu/meetings/dunes2012/pdf/7002.pdf>.

Zimbelman, J.R., Scheidt, S.P., 2012. Topographic profiles across a large reversing dune, to aid in evaluating the reversing dune hypothesis for TARs on Mars. In: Third International Planetary Dunes Workshop: Remote Sensing and Image Analysis of Planetary Dunes. Flagstaff, Arizona, abst. \#7003. <http:// www.lpi.usra.edu/meetings/dunes2012/pdf/7003.pdf $>$.

Zimbelman, J.R., in review/this issue. Recent developments in planetary aeolian studies and their terrestrial analogs. Aeolian Research. 